\title{
Seção temática: Gênero e políticas públicas Movimentos de mulheres do campo e o Estado: um estudo sobre as políticas voltadas ao enfrentamento da violência contra a mulher na realidade rural
}

Mariana de Lima Campos

Fundação João Pinheiro (FJP)

Flávia de Paula Duque Brasil

Fundação João Pinheiro (FJP)

O reconhecimento das mulheres do campo enquanto sujeitos de direitos e a construção de políticas voltadas para suas agendas específicas têm como base ações coletivas protagonizadas historicamente por trabalhadoras rurais em todas as regiões do país. Este trabalho analisa a atuação dos movimentos de mulheres e seus papéis na formação das políticas voltadas ao enfrentamento da violência contra a mulher do campo. Parte-se da discussão dos movimentos sociais, seus repertórios de ação e de interação com o Estado, enfatizando as possibilidades de influenciarem as políticas públicas. Aborda-se a construção dessas políticas no âmbito nacional com a incidência dos movimentos de mulheres e, especificamente, o foco analítico detém-se na forma como essas iniciativas vêm sendo desenvolvidas em Minas Gerais. Ressaltam-se os efeitos da interação entre os movimentos de mulheres do campo e o Estado na concepção das iniciativas em nível nacional apesar de evidenciarem-se os desafios em nível subnacional no que se refere à absorção e tradução de suas demandas.

Palavras-chave: políticas públicas, mulher, violência contra a mulher, zona rural, movimento social, Estado e sociedade

[Artigo recebido em 14 de julho de 2017. Aprovado em 12 de setembro de 2017.] 
Movimientos de mujeres del campo y el Estado: un estudio sobre las políticas dirigidas al enfrentamiento de la violencia contra la mujer en la realidad rural

El reconocimiento de la mujer del campo como sujetos de derechos y la construcción de políticas dirigidas a sus agendas específicas se basan en acciones colectivas protagonizadas históricamente por las trabajadoras rurales en todas las regiones del país. Este trabajo analiza el rendimiento de los movimientos de la mujer y su papel en la formulación de políticas encaminadas a combatir a la violencia contra las mujeres en el campo. Parte de la discusión de los movimientos sociales, sus repertorios de acción e interacción con el estado, haciendo hincapié en las posibilidades de influir en las políticas públicas. Discute la construcción de estas políticas en el plano nacional con la incidencia de los movimientos de la mujer y, concretamente, el análisis se centra en cómo esas iniciativas se desarrollan en Minas Gerais. Hacemos hincapié en los efectos de la interacción entre los movimientos de mujeres y el estado en el diseño de iniciativas a nivel nacional a pesar de las pruebas a los desafíos en el plan subnacional en relación con la absorción y la traducción de sus demandas.

Palabras clave: políticas públicas, mujer, violencia contra la mujer, zona rural, movimiento social, Estado y sociedad

Movements of rural women and the State: a study on policies aimed at fighting violence against women in the reality of rural

The recognition of rural women as subjects of rights and the construction of policies geared to their specific agendas are based on collective actions led historically by rural workers in all regions of the country. This paper analyzes the performance of the movements of women and their roles in the formulation of policies aimed at fighting violence against rural women. It starts with the discussion of social movements, their repertoires of action and interaction with state, emphasizing the possibilities to influence public policies. Discusses the construction of these policies at the national level with the incidence of women's movements and, specifically, the focus of analysis is on how these initiatives are being developed in Minas Gerais. We emphasize the effects of the interaction between women's movements and the State in the design of initiatives at the national level in spite of evidence to the challenges in the subnational level in relation to the absorption and translation of their demands.

Keywords: public policy, women, violence against women, social movement, State and society 


\section{Introdução}

Os movimentos sociais têm sido abordados a partir de diferentes chaves e desenvolvimentos teóricos (ALONSO, 2009; GOHN, 1997) que apontam para distintas possibilidades de sua incidência ou influência nas políticas públicas. No contexto das últimas décadas, destaca-se a pluralização das formas e repertórios de ação coletiva (WARREN, 2002) assim como de repertórios de interação dos movimentos com o Estado (ABERS; SerAfiM; TATAgIBA, 2014). Os movimentos sociais têm atuado não apenas na linha do ativismo insurgente e oposicional, como também em formas de ação mais institucionalizadas que envolvem diálogo e cooperação com o Estado, que ganham expressão no ambiente brasileiro pós-1988.

No campo sociopolítico dos movimentos que lutam por transformações sociais abrangentes, as mulheres rurais - enquanto sujeitos coletivos - têm buscado nas últimas décadas o reconhecimento do seu trabalho e de seus direitos de cidadania, além de mudanças nas formas como se estabelecem as relações de gênero no campo, atuando de diversas formas e pautando políticas públicas que se voltem às suas agendas e demandas específicas.

Tem-se como proposta analisar a atuação dos movimentos de mulheres do campo, suas formas de ação coletiva e de relação com o Estado, tendo em vista compreender como esses movimentos incidiram no processo de formação de políticas públicas e iniciativas voltadas ao enfrentamento da violência contra a mulher do campo, bem como no processo de implementação dessas iniciativas em nível subnacional, por meio de formas de acompanhamento e controle social. Tem-se como foco analítico específico a abordagem das formas como vem se dando a interlocução entre a Articulação de Mulheres do Campo de Minas Gerais (AMC) e o poder público no estado de Minas Gerais. Pretende-se dessa forma buscar uma melhor compreensão sobre o processo de institucionalização de instrumentos para o enfrentamento à violência contra as mulheres do campo, diante das perspectivas e interesses dos movimentos de mulheres do campo em trazer ao âmbito das políticas públicas um fenômeno social constantemente silenciado e invisibilizado.

O trabalho, que resulta de uma dissertação de mestrado, constitui-se como um estudo exploratório e de natureza qualitativa. Como recursos metodológicos, além da revisão bibliográfica e de levantamentos documentais, foram realizadas 
entrevistas semiestruturadas com integrantes da AMC e com representantes do poder público no que se refere as análises referentes ao nível subnacional ${ }^{1}$.

$\mathrm{O}$ artigo desenvolve-se em três seções, além desta introdução e considerações finais. Parte-se de uma breve revisão da literatura sobre movimentos sociais, destacando suas possibilidades de influência nas políticas públicas, por meio de mobilizações e de interações com o Estado. Em seguida, aborda especificamente como os movimentos de mulheres têm atuado e como afetaram a formulação de políticas nacionais voltadas ao enfrentamento da violência contra a mulher do campo. Especificamente abordam-se, então, como os movimentos de mulheres incidem sobre o processo de implementação das iniciativas desenvolvidas em Minas Gerais. Em um balanço, as considerações finais indicam os efeitos e as potencialidades das ações resultantes dos processos de mobilização, organização e participação dos movimentos de mulheres para a concepção das iniciativas existentes atualmente, evidenciando, por outro lado, os desafios para o enfrentamento do fenômeno da violência no meio rural em nível subnacional.

\section{Movimentos sociais e diferentes possibilidades de ação e interação com o Estado}

No contexto das transformações ocorridas na sociedade a partir dos anos 1960 ampliaram-se e pluralizaram-se as formas de ação coletiva, colocando em cena novos movimentos sociais (WARREN, 2002), entre os quais os movimentos feministas, pacifista, de direitos humanos e ambiental.

\footnotetext{
${ }^{1}$ Destaca-se a existência de dois momentos com recursos metodológicos distintos. Foram realizadas entrevistas semiestruturadas individuais com lideranças de alguns movimentos de mulheres do campo, integrantes da Articulação de Mulheres do Campo de Minas Gerais (AMC), e com responsáveis pela condução das principais ações de enfrentamento à violência contra as mulheres do campo no estado de Minas, sendo eles a Subsecretaria de Políticas para as Mulheres do Estado de Minas Gerais (SPM-MG), a Associação dos Municípios da Microrregião do Médio Jequitinhonha (AMEJE) e Secretaria de Assistência Social e Habitação (SEMAS) do município de Ponte Nova. Outro momento refere-se a uma entrevista coletiva - cujo teor foi utilizado na pesquisa - realizada com lideranças da AMC, parte da Pesquisa "Mulheres do Campo de Minas Gerais: trajetórias de vida, de lutas e de trabalho com a terra", realizada pela Fundação João Pinheiro (FJP) e Secretaria de Desenvolvimento Agrário de Minas Gerais (SEDA) (2015-2017). Nos dois momentos foram contemplados os seguintes movimentos sociais, sindicais, organizações e redes que representam as mulheres do campo de Minas Gerais: Articulação Metropolitana da Agricultura Urbana (AMAU), Articulação Nacional de Agroecologia (GT Gênero/ANA), Coletivo de Mulheres Organizadas do Norte de Minas, Comissão em Defesa dos Direitos das Comunidades Extrativistas (CODECEX), Federação das Comunidades Quilombolas do Estado de Minas Gerais, Federação dos Trabalhadores da Agricultura (FETAEMG), Federação dos Trabalhadores da Agricultura Familiar de Minas Gerais (FETRAF-MG), Marcha Mundial das Mulheres (MMM), Movimento de Mulheres da Zona da Mata e Leste de Minas, Movimento do Graal no Brasil e Movimento dos Trabalhadores Rurais Sem Terra (MST).
} 
Como indica Alonso (2009), o quadro de mobilizações daquele período deu-se, predominantemente, fora de instituições políticas, coordenadas e protagonizadas por diferentes sujeitos que levantavam bandeiras que iam além da redistribuição de recursos ou conflitos baseados em classe, demandando, também, a afirmação da diversidade e de estilos de vida, mudanças sociais e culturais. Apresentaram-se, assim, novas abordagens e desenvolvimentos teóricos tendo em vista compreender esses fenômenos.

A partir da revisão das diferentes perspectivas, destacam-se nesta seção as possibilidades da interação dos movimentos sociais com o Estado, tendo em vista sua incidência ou influência nas políticas públicas, ponto que tem recebido relativamente pouca atenção na literatura da área.

A própria noção de movimentos sociais não constitui uma concepção única na literatura, mas tem sido empregada de forma fluida. A despeito das diferenças entre as abordagens, constituem elementos-chave na caracterização dos movimentos sociais sua natureza coletiva, seu caráter primariamente informal e extra-institucional. Mais além, os movimentos têm sido associados à expressão de conflitos sociais e aos horizontes de mudança social (Alonso, 2009; GoHN, 2008; Della PORTA; DiAnNI, 1999). Nessa linha, em busca de uma caracterização que encampasse elementos das diferentes correntes, Della Porta e Dianni (1999) consideram os movimentos sociais como redes de interações informais aglutinando uma pluralidade de indivíduos e grupos engajados em confronto político ou ancoradas em elementos culturais e identidades coletivas compartilhadas.

Dentre as perspectivas, destaca-se aqui a demarcação de Jean Cohen (1985) de duas tradições teóricas de maior envergadura de abordagens sobre movimentos sociais a partir dos anos 1960 , postas não apenas como distintas, mas como competitivas. A autora considera os autores norte-americanos desde a Teoria de Mobilização de Recursos (TMR) às suas reformulações posteriores como um primeiro polo, que concebe a ação coletiva como estratégica, enquanto considera os autores europeus como um segundo polo, que se orienta para a identidade e privilegia a dimensão cultural na concepção de "novos movimentos sociais".

Em linhas muito gerais, na vertente norte americana, a Teoria da Mobilização de Recursos (TMR) constitui a base inicial, a qual enfatizava a dimensão estratégica e instrumental das ações coletivas por meio de aspectos racionais e organizacionais. A Teoria do Processo Político (TPP) constitui uma reformulação dessa perspectiva que assimila aspectos históricos e culturais. Por outro lado, a abordagem europeia, constituída pela produção de diferentes autores europeus em torno da categoria Novos Movimentos Sociais (NMS) enfatiza a dimensão da cultura e a construção de identidades coletivas a partir do cotidiano partilhado de seus participantes e de suas reivindicações. 
Cohen (1985) aponta para a insuficiência dessas concepções que apresentam alternativas excludentes para compreender formas de ação coletiva contemporâneas. A autora aponta para o substrato comum dessas tradições que se contrapõem às abordagens da primeira metade do século 20.2 Para Cohen e Arato (1992), ambas as tradições consideram que a ação coletiva conflitual é normal e que os integrantes dos movimentos sociais são racionais e integrados. Além disso, os autores afirmam que ambas as correntes apontam para os grupos organizados, associações autônomas e redes sociais como uma base para as ações coletivas e mobilizações, e consideram possibilidades de influência dos movimentos sociais nos domínios institucionais.

Visando a ultrapassar os limites das referidas concepções, Cohen e Arato (1992) desenvolvem a teoria da sociedade civil, moldada já no contexto de transformações do final dos anos 1980, marcado pela queda do muro de Berlim e dos regimes socialistas do leste europeu, ao lado da crescente pluralização das bandeiras dos movimentos sociais, sobretudo endereçadas ao reconhecimento de identidades coletivas. Ainda nessa linha, os autores consideram novas formas de ação coletiva nas sociedades contemporâneas, para além da perspectiva marxista que sustenta as relações de classe como chave exclusiva para abordagem dos conflitos sociais.

Os autores concebem a sociedade civil como um domínio autolimitado e autônomo que, com suas associações e organizações intermediárias, constitui o espaço de reunião, de organização e de mobilização dos atores sociais. Cohen e Arato (1992) vão além das perspectivas dicotômicas das correntes norte-americanas e dos novos movimentos sociais, defendendo uma dupla lógica e orientação da ação coletiva contemporânea. Nessa linha, a noção de sociedade civil concebe os atores sociais emergentes e sua arena de atuação em distinção ao Estado e ao mercado, enfatizando o âmbito o mundo da vida e a interação comunicativa, considerando que a ação coletiva contemporânea teria uma orientação identitária, mas também estratégica no que se refere à busca de influenciar ou afetar o sistema institucional.

Entretanto, considerando as linhas e desenvolvimentos teóricos referenciados, destaca-se que as interações entre movimentos sociais e o sistema institucional têm sido relativamente pouco contempladas. Ao considerarmos o contexto latinoamericano e notadamente no caso brasileiro, os movimentos sociais têm atuado com um repertório variado de ações coletivas nas últimas décadas, não restritas aos processos de organização, construção de identidades coletivas e mobilizações, encampando também formas de ação mais institucionalizadas tendo em vista sua

\footnotetext{
${ }^{2}$ Em linhas gerais, nas concepções da primeira metade do século, não raro o comportamento coletivo é tido como resposta disruptiva e irracional à mudança e desorganização social e os participantes considerados como desajustados e associados às premissas de comportamentos irracionais do comportamento coletivo (COHEN; ARATO, 1992; GoHN, 1997). Para uma revisão de tais correntes, ver Gohn (1997).
} 
incidência nas políticas públicas. Nesse sentido, como posto por Dagnino (2002), desde o ambiente de democratização do país, ao lado de uma inflexão na disposição dos movimentos sociais que reivindicam canais de participação institucionalizada, ampliaram-se tais possibilidades mediante a criação de instituições participativas ${ }^{3}$, ao lado de outras formas de interação entre atores coletivos e o Estado.

Carlos (2015) demonstra como a separação analítica presente nas diferentes abordagens sobre movimentos sociais entre sociedade civil e Estado - enquanto esferas autônomas e dicotômicas - é um fator que prejudica a compreensão sobre as possíveis formas de interdependência e influência entre esses dois domínios. Essa também é a constatação de Abers e Von Bülow (2011), ao analisarem como as relações entre sociedade e Estado são compreendidas nas teorias dos movimentos sociais que, na concepção das autoras, não têm se mostrado úteis para a compreensão das múltiplas formas de interação entre os movimentos sociais e o Estado.

Dessa maneira, uma noção que se mostra importante ao nos remeter às diferentes formas possíveis de relação entre movimentos sociais e o Estado é a de "repertório de interação Estado-sociedade" (ABERS; Serafim; TATAgIBA, 2014). Ainda a partir das autoras, o repertório de interação é composto por um conjunto de ações, como a participação institucional, o protesto, o lobby, a ocupação de cargos públicos, as relações políticas de proximidade ou diretas, podendo envolver para além de conflitos e contestação, práticas de diálogo e colaboração mútua. Nessas interações, os movimentos combinam e transformam suas estratégias de ação de acordo com seus objetivos múltiplos.

Assim, pode-ser dizer que, ao considerarmos a diversidade das formas de ação coletiva e interações socioestatais, é possível uma compreensão mais ampla acerca da atuação de um movimento social e dos possíveis efeitos e transformações, tanto em relação à sociedade civil, quanto em relação ao Estado (DowBOR, 2014; CARLOS, 2015). É possível abranger o olhar para os eventuais vínculos e ações de colaboração (e não só de conflito) entre os movimentos com o Estado, como ainda para as possibilidades de sua atuação dentro do aparato estatal (DAGNINO, 1994; ABers; Von Bülow, 2011; Abers; Serafim; TATAgIBA, 2014), permitindonos o reconhecimento das múltiplas relações e dos diferentes processos de ação coletiva que podem cruzar as fronteiras entre sociedade e Estado, evidenciando a impossibilidade de separarmos de forma rígida essas duas dimensões nos estudos sobre movimentos sociais (ABERS; VON BüLOW, 2011).

\footnotetext{
${ }^{3}$ Avritzer (2008) desenvolve o conceito de Instituições Participativas (IP) como formas diferenciadas de incorporação da sociedade civil que possibilitam aos atores sociais deliberarem sobre políticas públicas. São exemplos os conselhos gestores de políticas públicas, orçamentos participativos e as conferências realizadas nos diferentes níveis de governo.
} 
Para a finalidade deste trabalho, que perpassa pelo papel dos movimentos de mulheres do campo no âmbito das políticas públicas de enfrentamento à violência contra as mulheres, se faz importante destacar para além de sua organização e dimensão identitária, as formas de ações coletivas, os repertórios de interação entre os movimentos sociais e o Estado, e as possibilidades de sua influência nas políticas públicas tendo em vista o reconhecimento de suas agendas específicas.

\section{Movimentos de mulheres e a institucionalização de instrumentos para o enfrentamento à violência contra as mulheres do campo}

Num cenário no qual se destacam novos movimentos sociais que se mobilizavam em face de uma dimensão identitária e cultural da ação coletiva (MELUCCI, 2001; ALONSO, 2009; GOHN, 1997), as mulheres se organizavam com vistas a evidenciar suas condições de vida, lutar pela redefinição de seu papel social, buscar o reconhecimento de direitos em todas as esferas e propor mudanças políticas e culturais, inscrevendo suas demandas na agenda contemporânea.

Foi a partir da consolidação do movimento feminista e de mulheres no Brasil (TELES, 1993; PINTO, 2003; SARTI,1988), que se abriu espaço para que as mulheres em sua multiplicidade de vivências numa realidade social, marcada por diferentes clivagens, tais quais as mulheres do campo, pudessem passar a refletir sobre suas condições de vida, compartilhar perspectivas e significados, reivindicar direitos por meio do reconhecimento de suas identidades e se organizar em diferentes repertórios de ação em direção às mudanças tanto no âmbito da sociedade civil quanto dos domínios institucionais ${ }^{4}$. Compreende-se que a atuação do movimento feminista pavimentou um caminho de possibilidades e oportunidades para que mulheres, em sua diversidade, pudessem passar a exercer o seu direito de participação política e social.

Nesse contexto foi que houve condições para que se consolidassem movimentos específicos de mulheres rurais (DEERE, 2004 APUD SILIPRANDI, 2015). Mesmo já estando presentes nas lutas dos agricultores brasileiros, as mulheres do campo nem sempre contaram com a visibilidade de sua participação e perspectiva de luta. A organização de mulheres rurais enquanto sujeitos coletivos deu-se no sentido de questionar as estruturas vigentes das quais se viam excluídas, buscando no

\footnotetext{
${ }^{4}$ Segundo Farah (2004, p.51), foi sob impacto dos movimentos feministas na década de 1980, por tematizarem a transformação da situação das mulheres na sociedade, que passaram a ser implantadas as primeiras políticas públicas com recorte de gênero, ou seja, políticas que visam ao reconhecimento das diferenças/desigualdades de gênero e a implementação de ações diferenciadas para mulheres. Dessa forma, destaca-se sobremaneira o papel desses movimentos para "a inclusão da questão de gênero na agenda pública como uma das desigualdades a serem superadas por um regime democrático".
} 
contexto dos anos 1980, dentre outras questões, o acesso à terra, o reconhecimento da profissão de trabalhadora rural e sua cidadania, além de questionar a institucionalidade dominante e as relações de poder baseadas nas hierarquias de gênero no âmbito da própria família (OKIN, 2008), principalmente pela aproximação com os ideários feministas (SILIPRANDI, 2015).

O resultado das ações protagonizadas ao longo dos anos por trabalhadoras rurais em todas as regiões do país, por meio de sua capacidade mobilizatória em diferentes movimentos e grupos organizados, deu origem, em 2000, à Marcha das Margaridas ${ }^{5}$, uma das maiores manifestações populares que ocorrem atualmente no país (SILVA, 2008). Constituiu-se enquanto um repertório novo de ação coletiva, no sentido de que as experiências locais de mobilização aprendidas e compartilhadas em diferentes escalas organizacionais se transformaram estrategicamente em uma nova forma de ação de protesto, bem como de negociação com o aparato estatal.

Seu intuito principal é tornar pública suas condições de vida, as situações de desigualdade vivenciadas no meio rural e as diversas formas de violência por elas enfrentadas como consequência da cultura patriarcal que as tem colocado na invisibilidade e as tem excluído historicamente das políticas públicas. As principais questões demandadas pelas mulheres rurais ao longo dos anos perpassam essencialmente pela percepção de seu lugar enquanto atores sociais e políticos.

Assim, milhares de mulheres do campo têm se organizado em diversos movimentos e entidades, se articulando em diferentes municípios e estados brasileiros, privilegiando diversas lógicas de ação coletiva.

Esses movimentos vêm promovendo suas lutas em torno de objetivos comuns, conquistando a visibilidade e um gradual reconhecimento de suas demandas junto ao Estado (SILVA, 2008). Para além da atuação mobilizatória e de ativismo, nos últimos anos ampliou-se ainda a participação dessas mulheres em instituições participativas como conselhos, fóruns e conferências (SILIPRANDI; CINTRÃO, 2015). Ressalta-se a existência da participação de segmentos organizados de mulheres do campo, por exemplo, em espaços como o Conselho Nacional de Políticas

\footnotetext{
${ }^{5}$ A Marcha das Margaridas é uma ação estratégica de mulheres do campo, das florestas e das águas, coordenada pelo movimento sindical rural, por meio da Confederação Nacional dos Trabalhadores na Agricultura (Contag), suas 27 Federações de Trabalhadores na Agricultura (Fetags) e sindicatos de Trabalhadores e Trabalhadoras Rurais (STTRs) de diferentes regiões do país, em articulação com a plataforma política do movimento feminista, tendo diversos movimentos e organizações de mulheres parceiras, como a Marcha Mundial das Mulheres, a Articulação de Mulheres Brasileiras, o Movimento Articulado de Mulheres da Amazônia, o Movimento Interestadual das Quebradeiras de Coco de Babaçu, o GT Gênero da Articulação Nacional de Agroecologia e a Rede de Mulheres Rurais da América Latina e Caribe, por exemplo, além da Central Única dos Trabalhadores (CUT), do Conselho Nacional das Populações Extrativistas, da Confederação de Organizações de Produtores Familiares, Campesinos e Indígenas do Mercosul Ampliado, entre outros.
} 
para as Mulheres e nas conferências nacionais realizadas sobre o mesmo tema enquanto entidades representantes da sociedade civil, com o foco na construção, em interlocução com representantes governamentais, de estratégias de ação para elaboração de políticas públicas voltadas para a promoção dos direitos da mulher e para o reconhecimento de sua cidadania. Assim, é possível perceber a existência de diferentes formas de interação (ABERS; VON BüLOW, 2011; CARLOS, 2015) entre esses movimentos e o Estado ${ }^{6}$.

O que se pode afirmar em relação ao âmbito federal, é que nos últimos governos, assumidos pelo Partido dos Trabalhadores (PT), "foram visíveis os esforços no sentido de acolher as demandas oriundas desses movimentos e transformá-las em políticas e ações com enfoque de gênero e que visassem diminuir as iniquidades no meio rural" (SILIPRANDI; CINTRÃo, 2015, p. 573). As iniciativas hoje existentes, mesmo que timidamente, são, de fato, respostas às demandas de mulheres rurais em suas diferentes formas de organização, manifestação (HEREDIA; CINTRÃo, 2006) e de relação com o Estado, considerando principalmente, o repertório de interação sociedade - Estado (ABERS; SERAFIM; TATAGIBA, 2014) nas áreas a que se referiam as políticas para as mulheres nos últimos anos.

Matos (2016), em um estudo recente e ainda parcial, demonstra, analisando iniciativas de políticas relacionadas a gênero promovidas pelo poder público desde a redemocratização do país até o ano de 2015, como as iniciativas estatais relacionadas a gênero e sexualidade implantadas de 2003 a 2015, "Era PT", aumentaram em escala e magnitude, com expressividade das políticas para as mulheres ${ }^{7}$. A autora atribui a essa fase a existência de "contornos de aprofundamento dos processos popularparticipativos que culminaram na elaboração de uma significativa rede de políticas públicas de reconhecimento, antidiscriminatórias e de inclusão democrática" de grupos considerados subalternos, demonstrando como os governos desse período se deixaram permear mais do que nos períodos anteriores (1988-2002) pela agenda reivindicatória dos movimentos de mulheres e feministas, transformando demandas em pautas efetivas de ação governamental.

\footnotetext{
${ }^{6}$ Ressalta-se de uma forma geral uma ampla participação institucional das mulheres no país a partir do ano de 2003 por meio da realização das primeiras Conferências de Políticas para as Mulheres, convocadas pela então Secretaria de Políticas para as Mulheres da Presidência da República (SPM-PR) e pelo Conselho Nacional dos Direitos da Mulher (CNDM), que embasaram a construção coletiva entre governo e sociedade civil de três Planos Nacionais de Políticas para as Mulheres que sistematizam as diretrizes e ações de promoção à igualdade de gênero vigentes até então no país (SECRETARIA DE PolítICAS PARA AS MULHERES, 2011b).

${ }^{7}$ O estudo demonstra que no período de 1988 a 2002, a agenda setorial prioritária de políticas públicas esteve associada a áreas como Saúde, Direitos e Justiça, Trabalho e Previdência, referentes a pautas universais. Já no período de 2003 a 2015, áreas setoriais como Participação e Representação, Trabalho e Previdência e Violência contra a Mulher, por exemplo, obtiveram aumento expressivo, demonstrando prioridades da agenda governamental do período alinhadas às propostas programáticas do Partido dos Trabalhadores (MATOS, 2016).
} 
Entretanto, apesar de importantes conquistas em relação à agenda de direitos das mulheres brasileiras, quando considerada a realidade das mulheres do campo percebe-se que muitas dificuldades ainda fazem parte de seu cotidiano, entre elas, é possível citar a precariedade da infraestrutura no meio rural brasileiro no que se refere ao acesso a serviços básicos, a sua recorrente não identificação enquanto trabalhadoras na agricultura, a falta de autonomia econômica, o acesso efetivo à titularidade da terra e a iniciativas voltadas ao enfrentamento da violência contra a mulher, por exemplo. A análise aqui proposta se volta a essa última questão.

O progressivo questionamento e reconhecimento do fenômeno da violência contra as mulheres, bem como da necessidade de seu enfrentamento, fez com que o tema se tornasse objeto de diversas formas de institucionalização, principalmente por meio da "Lei Maria da Penha ${ }^{8}$ e todo um conjunto de políticas e aparatos a ela ligados" construídos numa perspectiva de incidência dos movimentos de mulheres e feministas (GUTERRES; Aguĩ̃o, 2014, p. 234). Por muito tempo negligenciados, os casos de violência passaram a ganhar visibilidade diante das lutas e reivindicações desses movimentos para que fossem reconhecidos enquanto um problema social, tornando-os públicos, pois até então eram considerados restritos ao âmbito privado.

A realidade das mulheres do campo traduz as múltiplas faces da violência existentes no contexto rural, violências que se materializam em seus corpos. Através de uma cartografia da violência contra as mulheres do campo e da floresta, Daron (2009), ressalta que o contexto cotidiano dessas mulheres é "marcado pela sobrecarga do trabalho (de sol a sol na roça, o cuidado com a casa, com os filhos, comida, roupas, animais, pomar, horta, entre outras tarefas cotidianas), exploração, opressão e discriminação" (DARON, 2009, p.10), além das consequências do modelo capitalista que impacta na sobrevivência de todos os trabalhadores rurais. O fenômeno da violência contra as mulheres do campo não pode ser desvinculado desse contexto de vida. Ela se torna um instrumento para a manutenção e reprodução das relações desiguais entre homens e mulheres, considerando principalmente a divisão sexual do trabalho e a definição de papéis sociais diferenciados legitimados pelo sistema patriarcal, que as silencia, delega a responsabilidade por todo o trabalho doméstico, condiciona seus comportamentos e as destina à esfera privada9. Soma-se a essas especificidades o contexto de distâncias, o que faz com que se torne uma violência invisibilizada.

\footnotetext{
${ }^{8}$ Lei no 11.340 , de 2006.

${ }_{9}$ Destaca-se que, no cotidiano das mulheres trabalhadoras rurais, o espaço da moradia é o mesmo do trabalho, e, portanto, os agressores são em sua maioria os mesmos da convivência familiar e do trabalho, sendo um elemento diferenciado do contexto urbano (DARON, 2009, p.59).
} 
Na realidade do campo, as desigualdades de gênero são, assim, acompanhadas ainda de outras desigualdades sociais, considerando a precariedade de infraestrutura e de serviços públicos recorrente nas zonas rurais, que impactam de maneira significativa a vida das mulheres (SILIPRANDI; CINTRÃO, 2015).

Em decorrência das dificuldades territoriais como também perante a desagregação e escassez de dados específicos sobre o fenômeno no âmbito rural (DARON, 2009), a interiorização das ações e políticas voltadas para o enfrentamento da violência se torna um desafio, o que faz com que normalmente não apareça como um ponto prioritário na ordem da pauta dos executivos municipais, estaduais e federal (SECRETARIA DE PolítICAS PARA AS MULHeRes, 2011a). Nesse sentido, o acesso às políticas de combate à violência se torna ainda mais difícil para as mulheres do campo, sendo necessárias reflexões em torno de alternativas que incidam sobre o problema a partir de suas realidades específicas e necessidades diferenciadas.

Diante desse contexto de dificuldades de acesso às políticas públicas, experiências baseadas em processos de auto-organização e diálogo com a sociedade têm sido desenvolvidas por parte de militantes rurais para tornar público o debate sobre a violência e sobre a necessidade do reconhecimento de direitos e de justiça social. A luta e a mobilização das mulheres do campo se constituem como formas de chamar a atenção da sociedade e do Estado sobre sua condição de vida e de violência historicamente invisibilizados (DARON, 2009, p.82), na busca de soluções imediatas e simbólicas, que incidam sobre uma perspectiva cultural de transformação das relações sociais, seus direitos à sobrevivência e a uma vida sem violência. Essas mulheres, organizadas, vem desenvolvendo lutas, campanhas e ações cotidianas de denúncia, resistência e de caráter educativo para a superação de todas as formas de violência contra as mulheres ${ }^{10}$, objetivando uma sociedade mais igualitária, impactando inclusive no âmbito da formulação de políticas públicas por meio de sua organização.

Atendendo as demandas e reivindicações históricas dos principais movimentos e organizações de trabalhadoras rurais para que esse tema pudesse constar na agenda pública, foram publicadas em 2011, por meio da então Secretaria de Políticas para as Mulheres da Presidência da República (SPM-PR), as Diretrizes e Ações de Enfrentamento à Violência contra as Mulheres do Campo e da Floresta (SECRETARIA de Políticas PARA AS MulHeRes, 2011a). Essas diretrizes retomam a Política e o Pacto Nacional pelo Enfrentamento da Violência contra

\footnotetext{
${ }^{10} \mathrm{Um}$ exemplo a ser destacado é a "Campanha mundial da Via Campesina para acabar com as violências contras as mulheres” lançada em sua 5a Conferência Internacional em Moçambique (2008) (DARON, 2009, p.83).
} 
as Mulheres e as ações previstas nesses instrumentos, somando-se à existência do Fórum Nacional de Enfrentamento à Violência contra as Mulheres do Campo e da Floresta, criado em 2007, no sentido de ser um canal permanente de diálogo entre a sociedade civil e representantes governamentais, na tentativa de ampliar o alcance das políticas públicas para que pudessem ser formuladas em novas bases com vistas a serem adequadas às realidades locais (SECRETARIA de Políticas para As Mulheres, 2011a).

A luta das mulheres do campo e da floresta aliada a essas iniciativas, na concepção de Daron (2009, p. 84), são alguns marcos fundamentais para o desvelamento e a tomada de posição para transformar a realidade das mulheres do campo, marcada por um cotidiano de violências, produzindo até então no país "um espaço inovador no campo das políticas públicas" voltadas a essas mulheres em sua diversidade.

Como forma de que pudessem ser implementadas as diretrizes e ações então instituídas, destaca-se a criação das Unidades Móveis de Atendimento às Mulheres do Campo e da Floresta em Situação de Violência, projeto anunciado em 2011 pelo Governo Federal, vindo a se concretizar enquanto uma também conquista da Marcha das Margaridas a partir de 2013, frente às reivindicações para que essas mulheres, com toda a dificuldade de acesso a que estão submetidas, pudessem dispor de alguma alternativa para receber informação e atendimento em relação à violência.

Essas unidades móveis são ônibus adaptados para levar às áreas mais remotas e afastadas dos centros urbanos, onde residem populações com menores condições de acesso, os serviços especializados da rede de atendimento às mulheres em situação de violência, incorporados ao Programa "Mulher, Viver sem Violência", da SPM-PR, no eixo referente à interiorização e capilarização das políticas públicas de enfrentamento à violência contra as mulheres, parte de uma tentativa de materializar as diretrizes do Pacto Nacional de Enfrentamento à Violência contra as Mulheres de forma descentralizada nas áreas mais distantes dos serviços normalmente oferecidos.

As discussões, o planejamento e o monitoramento das ações relativas ao tema seriam atribuições dos Fóruns Estaduais de Enfrentamento à Violência contra as Mulheres do Campo e da Floresta, que deveriam ser criados no âmbito dos estados, como espaços de participação e deliberação compostos por representantes governamentais e da sociedade civil.

Diante da trajetória de luta ao longo dos anos em distintos repertórios de ação e interação com o Estado, destaca-se, assim, o protagonismo dos movimentos e organizações de mulheres do campo. 
O papel dos movimentos foi de fundamental importância pras políticas que existem, se não tivesse essa pressão, essa organização, essa demanda dos movimentos junto ao poder público, a gente não teria conquistado nada até agora, principalmente pras mulheres do campo. Quando fala assim que mulher do campo não trabalha, que mulher do campo é ajudante da família, aí você consegue uma linha de crédito específica pras mulheres, consegue criar um Fórum Nacional de Enfrentamento à Violência contra as Mulheres do Campo e agora estão sendo criados os fóruns estaduais, quando você consegue fazer com que a mulher tenha acesso a terra, tenha acesso à comercialização por que é prioridade para as mulheres hoje, então eu considero que isso é os movimentos sociais conseguirem cumprir o seu papel, estar conseguindo mostrar o seu papel na sociedade, dando visibilidade e credibilidade para as trabalhadoras rurais. (Entrevistada, integrante da FETAEMG)

Dessa forma, diante de sua trajetória de luta e participação, pode-se dizer que as mulheres do campo incidiram no âmbito das políticas públicas, sobretudo no que se refere à política nacional de enfrentamento à violência contra as mulheres, conseguindo construir em diálogo com o governo, em determinado cenário político em que se destacaram governos caracterizados por uma agenda de caráter inclusivo, iniciativas voltadas às singularidades da violência acometida contra as mulheres do campo e suas vivências até então não priorizadas, ou mesmo consideradas, pelo Governo Federal.

\section{Violência contra as mulheres do campo: movimentos de mulheres e as iniciativas desenvolvidas em Minas Gerais}

Apesar dos avanços constatados no que se refere às iniciativas federais, em nível subnacional, quando considerado o contexto de Minas Gerais percebe-se de uma forma geral uma falta de priorização na implementação de políticas públicas voltadas para as mulheres do campo. Até meados de 2007 não existia uma estrutura formal responsável pelas políticas para mulheres no governo. A criação da Coordenadoria Especial de Políticas para as Mulheres (CEPAM), vinculada à Secretaria de Estado de Trabalho e Desenvolvimento Social (SEDESE) não significou necessariamente uma mudança nesse quadro, mas apenas um rebatimento de políticas federais. Nitidamente, o estado apenas se adequou ao que foi proposto e executado pelo Governo Federal, em detrimento do desenho de políticas estaduais específicas aos seus desafios internos.

Contudo, em 2015, já no governo Pimentel (PT), a CEPAM deixou de existir, dando lugar a então criada Subsecretaria de Políticas para as Mulheres 
$(\text { SPM-MG })^{11}$ vinculada agora à Secretaria Estadual de Direitos Humanos, Participação Social e Cidadania do governo de Minas Gerais (SEDPAC-MG). Alinhada com a Política Nacional de Políticas para as Mulheres, a SPM-MG evidencia a pretensão de construir políticas de enfrentamento à violência contra as mulheres e de promoção da sua autonomia econômica. Entretanto, ao direcionar as análises às mulheres do campo, percebe-se ainda um desafio para que as suas necessidades possam ser traduzidas em termos de políticas públicas.

Atualmente, as iniciativas existentes voltadas especificamente ao enfrentamento da violência contra as mulheres do campo em Minas Gerais, resumem-se à existência do Fórum_Estadual de Enfrentamento à Violência contra as Mulheres do Campo, da Floresta e das Águas, composto por representantes governamentais e da sociedade civil, e de três Unidades Móveis de Atendimento às Mulheres do Campo e da Floresta em Situação de Violência.

O Fórum Estadual, criado em 2016 e coordenado pela SPM-MG, é uma iniciativa incipiente, mas um avanço na medida em que consiste em um canal de interlocução com o Estado, considerado importante por diferentes movimentos e organizações que representam as mulheres do campo do estado.

O Fórum de Enfrentamento à Violência contra as Mulheres do Campo, das Florestas e das Águas, faz parte de uma política nacional e nasce pela reivindicação das mulheres na Marcha das Margaridas, elas foram, marcharam e levaram uma carta com reivindicações para a presidenta Dilma, e entre as reivindicações estava a questão do estabelecimento desse Fórum e das unidades móveis. [...] As mulheres do campo trouxeram uma pauta de reivindicações e entre elas, estava a reivindicação do estabelecimento do Fórum no nível estadual. Então em diálogo com os parceiros e com os movimentos de mulheres do campo o Fórum ficou estabelecido e reúne tanto organizações do governo, quanto movimentos sociais... (Entrevistada representante da Subsecretaria de Políticas para as Mulheres do governo de Minas Gerais)

A existência desse Fórum é uma consecução da ação e interação das mulheres do campo com o governo de Minas, por meio da Articulação de Mulheres do

\footnotetext{
${ }^{11}$ A SPM-MG tem sua estrutura composta pela Superintendência de Enfrentamento à Violência contra as Mulheres e Superintendência de Autonomia Econômica das Mulheres e Articulação Institucional. Cabe ressaltar que a maior parte de suas integrantes são pessoas ligadas a movimentos sociais ou com trajetórias na militância em relação aos direitos das mulheres.
} 
Campo de Minas Gerais ${ }^{12}$, evidenciando, nesse sentido, um exemplo de como as mulheres do campo vêm tendo, em um período recente, diante de um governo que propôs o início de uma gestão mais "participativa" e inclusiva, um progressivo reconhecimento pelo poder público estadual enquanto atores coletivos.

Mesmo com identidades e pautas específicas, os movimentos, organizações e redes que representam essas mulheres em Minas Gerais se articulam desde meados de 2006, compondo uma agenda unificada de luta por direitos.

Essa articulação veio fortalecer os movimentos que já existem. Não é mais um movimento. Mas a gente agrupa todos os movimentos em um só. Então isso é uma força muito grande. (Entrevistada, integrante da FETRAF)

A Articulação tem esse objetivo, que é esse processo da gente articular os movimentos pra um processo de luta. Tanto pra questão das políticas públicas, mas também pra questão do nosso enfrentamento, das nossas reivindicações, de ter maior visibilidade pras trabalhadoras rurais e um processo de enfrentamento dos problemas cotidianos. A gente sabe que individualmente cada movimento, cuidando das suas trabalhadoras, é muito mais difícil de você conseguir conquistas efetivas nesse processo contra a opressão das mulheres. (Entrevistada, integrante da Marcha Mundial das Mulheres)

O estabelecimento desse vínculo as permite partilhar uma identidade coletiva que se apresenta como estratégia de visibilidade e busca pelo reconhecimento em relação ao Estado.

O repertório de ação coletiva da $\mathrm{AMC}$ envolve ações que têm como intuito buscar o fortalecimento das mulheres do campo em seus enfrentamentos diários, por meio da mobilização e lutas por transformações no âmbito das relações sociais. Também envolve ações mais institucionalizadas e estratégicas voltadas, por exemplo, a incidir sobre o âmbito das políticas públicas. A participação em canais institucionais e o estabelecimento de diálogo com o governo se constituem como o principal repertório de interação desses movimentos com o Estado em Minas Gerais, ainda que, por hora, não se possam evidenciar significativas absorções e traduções de suas demandas pelo Estado.

\footnotetext{
${ }^{12}$ Fazem parte a Articulação Metropolitana da Agricultura Urbana (AMAU), Coletivo de Mulheres Organizadas do Norte de Minas, Comissão em Defesa dos Direitos das Comunidades Extrativistas (CODECEX), Federação dos Trabalhadores da Agricultura (FETAEMG), Federação dos Trabalhadores e Trabalhadoras na Agricultura Familiar (FETRAF), Federação das Comunidades Quilombolas do Estado de Minas Gerais (N’Golo) - Coordenação Estadual das Mulheres Quilombolas, Grupo de Trabalho sobre Gênero e Agroecologia (GT Gênero) da Articulação Nacional de Agroecologia (ANA), Marcha Mundial das Mulheres (MMM), Movimento de Mulheres da Zona da Mata e Leste de Minas, Movimento do Graal no Brasil, Movimento dos Atingidos por Barragens (MAB) e o Movimento dos Trabalhadores Rurais Sem Terra (MST).
} 
A gente não pode falar que não tem abertura. Pelo menos diálogo nós temos, nós estamos construindo, participando de muitas reuniões. Por exemplo, nós temos a unidade móvel de enfrentamento à violência que foi uma conquista da Marcha das Margaridas e ta aqui em BH desde 2013, mas que agora que tá começando a funcionar, por que foi criado um Fórum Estadual de Enfrentamento à Violência contra as Mulheres do Campo e da Floresta. Então quer dizer, daquilo que tava parado já tem alguma coisa começando a funcionar [...] Tá caminhando, a passos lentos, não vamos falar que tá a passos longos não, por que não tá - tá a passos lentos. Pra quem não tinha nada, já tem alguma coisa acontecendo, mas a gente espera mais. (Entrevistada, integrante da FETAEMG)

O Fórum Estadual pode ser considerado como uma oportunidade política de participação institucional das mulheres do campo, praticamente inexistente em Minas Gerais até 2015, para tematizarem suas questões e incidirem nas ações relativas ao enfrentamento da violência contra as mulheres do campo.

Uma das funções atribuídas ao Fórum Estadual é versar sobre as discussões, o planejamento e o monitoramento das ações relativas às Unidades Móveis de Atendimento às Mulheres do Campo e da Floresta em Situação de Violência.

As Unidades Móveis estão localizadas em Belo Horizonte, Ponte Nova e na região do Vale do Jequitinhonha, na cidade de Araçuaí. De uma forma geral, pode-se dizer que as ações são empreendidas de formas pontuais e não articuladas, no sentido de levar informações sobre os direitos das mulheres, sobre a Lei Maria da Penha e sobre os serviços de acolhimento e atendimento disponíveis nos municípios que abrangem as comunidades atendidas.

As Unidades Móveis enfrentam dificuldades comuns para encampar ações mais eficazes. Dentre elas, destacam-se a falta de uma equipe própria para a condução das ações, a limitação existente de recursos para manutenção e abastecimento dos ônibus e a necessidade de capacitação dos profissionais da "ponta" no que se refere à complexidade que envolve o tema do enfrentamento da violência contra as mulheres. Nota-se uma preocupação geral associada a essa última dificuldade, no sentido de as ações requererem como base o fortalecimento e a articulação de redes locais de enfrentamento à violência a partir de uma mobilização intersetorial dos serviços de atendimento dos municípios abrangidos ${ }^{13}$, tendo em vista que é o que "fica" para as mulheres do campo após as visitas realizadas pelas Unidades.

As percepções dos movimentos sociais em relação às Unidades Móveis as evidenciam enquanto uma importante conquista das mulheres do campo para

\footnotetext{
${ }^{13}$ Para uma melhor compreensão sobre as Redes de Enfrentamento à Violência contra as Mulheres e sua importância, ver Pasinato (2015) e Secretaria de Políticas para as Mulheres - SPM (2011c).
} 
que existam possibilidades de atendimento às mulheres em situação de violência no meio rural, normalmente distantes desses serviços. Enfatizam, nesse sentido, o papel que tiveram na construção coletiva desse projeto durante a Marcha das Margaridas.

Entretanto, há o reconhecimento de que o número de Unidades disponíveis é insuficiente para que possa contemplar grande parte das comunidades rurais em Minas Gerais e suas demandas, existindo ressalvas relacionadas, inclusive, às formas pelas quais foram designadas as Unidades existentes em Minas Gerais às regiões em que se localizam atualmente, contrariando as propostas e percepções sobre o fenômeno da violência contra as mulheres do campo no estado advindas das trajetórias de lutas e envolvimento dos movimentos na realidade rural de Minas Gerais.

As unidades móveis que a gente sentou, ajudou a construir, falou como deveria funcionar, ajudou no processo de cabo a rabo e na hora de efetivar mesmo o projeto, de colocar pra funcionar, nós não somos beneficiadas. Quando nós construímos na Marcha das Margaridas essas unidades, elas foram construídas com os destinos certos. [...] Quer dizer, pra construir nós fomos importantes, sentamos e construímos o projeto, mas na hora de definir e de decidir pra onde iria, ninguém nos perguntou nada. [...] A gente fica um pouco indignada em relação a isso. Você perde tempo pra construir, pra ta lá e na hora das definições, ninguém pergunta nada a ninguém. Então assim, se essas unidades móveis cumprissem com o que nós colocamos no papel pensado pra elas, seria muito importante. (Entrevistada, integrante do Coletivo de Mulheres Organizadas do Norte de Minas)

O questionamento do papel das Unidades Móveis se dá, também, por suas ações não estarem, até o momento, direcionadas necessariamente às mulheres do campo, trabalhadoras rurais, às quais lutaram para que a demanda fosse de fato absorvida e traduzida em termos de política pública.

Ressaltam-se, assim, os entraves existentes na realidade rural para o enfrentamento da violência contra as mulheres, que perpassam essencialmente pelas dificuldades de acesso à informação e aos serviços de atendimento as quais enfrentam as mulheres no campo em suas experiências cotidianas, tendo em vista, principalmente, as distâncias existentes entre suas moradias, comunidades e municípios em que se localizam os serviços e equipamentos públicos, mas principalmente por sua invisibilidade e naturalização diante não só do enraizamento das desigualdades de gênero na sociedade, como também pela real falta de priorização do tema em termos de políticas públicas no estado. 
Nesse último sentido, enfatiza-se que o enfrentamento da violência contra as mulheres do campo requer uma efetiva priorização da temática sob uma perspectiva de gênero por parte das gestões governamentais em seus diferentes níveis para que possa constar em políticas e ações mais eficazes. Nessa direção, é preciso ainda que se torne imprescindível a percepção da importância de uma efetiva democratização de tais ações em seus processos de implementação, para que possam ser de fato permeáveis às reais necessidades das mulheres que vivem em comunidades rurais.

Diante dos entraves existentes, uma das alternativas evidenciadas é o processo de auto-organização das mulheres como um instrumento de enfrentamento às violações de direitos existentes no âmbito rural.

A gente conversa muito que uma das únicas saídas é você ter processos de organização mais coletiva, de auto organização das mulheres e nesses processos você consegue construir processos de solidariedade, por que, realmente, é muito difícil das mulheres romperem com a violência. (Entrevistada, integrante da Marcha Mundial das Mulheres)

Os movimentos sociais destacam-se, assim, enquanto importantes espaços não só de fortalecimento das mulheres por meio da internalização de perspectivas de mudanças - que mesmo não fáceis, se assumem enquanto primordiais para superação e enfrentamento da violência -, assim como são aqueles que encampam lutas de resistência contra o silenciamento e opressões patriarcais que tem constantemente reservado às mulheres do campo experiências cotidianas de invisibilidade e exclusão das políticas públicas, tematizando e demandando, assim, o reconhecimento de seus direitos e de justiça social, pela percepção das mulheres do campo enquanto atores sociais e políticos, por um bem viver e por uma vida sem violência.

De uma forma geral, no que se refere aos pontos a serem considerados para o enfrentamento do fenômeno da violência contra as mulheres do campo, evidenciam-se, essencialmente, seis questões centrais, quais sejam, a necessidade e relevância: 1) do estabelecimento de processos de auto-organização das mulheres no campo que reforcem sua conscientização sobre o tema, desnaturalização da violência, seu fortalecimento e empoderamento; 2) da priorização da temática em termos de políticas públicas; 3 ) de políticas formuladas sob uma perspectiva de gênero que se voltem à promoção da autonomia econômica e protagonismo das mulheres; 4) do aprimoramento dos serviços existentes de atendimento às mulheres, como também na dimensão da denúncia e da punição dos agressores 5) da sensibilização e a capacitação profissional continuada em relação às questões de gênero e à violência contra a mulher para que percebam a importância do tema e 
de um trabalho em rede, articulado e intersetorial; e 6) da priorização da educação como instrumento de transformação social capaz de desconstruir valores e práticas assentadas na desigualdade de gênero e opressões patriarcais, como fator basilar de promoção da equidade e construção da justiça social.

\section{Considerações finais}

Considerando o contexto brasileiro, os movimentos sociais têm atuado com um repertório variado de ações coletivas, tendo por objetivo influir ou incidir nas políticas públicas, visando, sobretudo, a aspectos relativos à inclusão social e à democratização. Essa atuação se dá não só por uma via oposicional e de contestação, como também por meio de distintas formas de participação institucional.

Diante desse cenário, os movimentos de mulheres do campo vêm buscando nas últimas décadas a construção e o reconhecimento de suas identidades coletivas e a conquista de direitos, com questionamentos e pautas que se endereçam a mudanças abrangentes no âmbito das relações sociais, como também das políticas públicas. Dessa forma, vêm promovendo as suas lutas em torno de objetivos comuns, conquistando visibilidade e um gradual reconhecimento de suas demandas e especificidades junto à sociedade e ao Estado.

A temática da violência contra as mulheres e a violação de direitos nas realidades rurais tem sido uma prioridade dos movimentos que envolvem as mulheres do campo. Ressaltam-se, apesar dos entraves existentes para que o fenômeno tenha visibilidade e possa ser enfrentado no meio rural, os efeitos e as potencialidades das ações resultantes dos processos de mobilização, organização e participação dos movimentos de mulheres do campo para a incidência nas políticas públicas em nível nacional e na formulação das iniciativas hoje existentes, destacando-se, sobremaneira, seu protagonismo em uma trajetória de avanços nos últimos anos.

Cabe ressaltar que a introdução da temática em uma perspectiva de gênero na agenda do Governo Federal, somente se deu em um contexto determinado de oportunidade política em que certos temas voltados à inclusão social e a conquista da cidadania passaram a ganhar ênfase e serem priorizados no âmbito das políticas públicas. Entretanto, em nível subnacional, quando considerado o contexto de Minas Gerais, percebe-se uma não priorização do tema da violência contra as mulheres do campo na formulação de políticas e ações no âmbito estadual, tendo em vista que as iniciativas implementadas decorrem do elaborado no nível federal, destacando-se enquanto um desafio a ser ainda equacionado.

Nesse sentido, ressalta-se o papel desempenhado pelos movimentos e organizações que compõem a Articulação das Mulheres do Campo de Minas Gerais 
ao tematizarem e demandarem nos últimos anos ao governo do estado, o seu reconhecimento enquanto ator coletivo e interlocutor para o acompanhamento e controle social das iniciativas voltadas a essa questão e, sobretudo, na constante busca de respostas às suas demandas específicas. Destaca-se que esse reconhecimento vem se dando diante de uma recente abertura estabelecida de diálogo, ainda que, por hora, não se possam evidenciar significativas absorções e traduções de suas demandas pelo Estado.

Apesar do processo estabelecido ao longo dos últimos anos de interação entre as mulheres do campo - enquanto atores coletivos - e o Estado, para que houvesse possibilidades de que se estruturassem transformações necessárias em termos de políticas públicas voltadas às suas singularidades de vida, de uma forma geral, nota-se que o atual cenário político brasileiro tem estabelecido medidas que vêm ameaçando direitos e conquistas populares, impactando substancialmente nas formas de interação entre movimentos sociais e o Estado, nas iniciativas formais e propostas de intervenções que garantam a promoção dos direitos das mulheres e de modo consequente, no enfrentamento da violência contra as mulheres do campo. Todavia, os próprios movimentos tematizam essas dificuldades e possíveis linhas de ações. Mesmo que não possam ser evidenciados resultados efetivos de maior envergadura diante das iniciativas aqui analisadas, pode-se observar um contínuo processo de organização por parte dos movimentos de mulheres do campo, de tematização de questões, de busca de incidência no âmbito das políticas públicas e de reflexividade em relação à própria ação coletiva no que se refere à constante busca pelo reconhecimento de direitos de cidadania, em defesa da equidade de gênero e a uma vida sem violência.

\section{Referências bibliográficas}

Abers, Rebecca; Serafim, Lizandra; TATAgIBA, Luciana. Repertórios de Interação Estado-Sociedade em um Estado Heterogêneo: A Experiência na Era Lula. DADOS Revista de Ciências Sociais, Rio de Janeiro, v. 57, n. 2, p. 325-357, 2014.

ABERS, Rebecca; VoN BüLow, Marisa. Movimentos sociais na teoria e na prática: como estudar o ativismo através da fronteira entre Estado e sociedade? Sociologias, Porto Alegre, ano 13, n.28, p. 52 -84, set/dez 2011.

Alonso, Ângela. As teorias dos movimentos sociais: um balanço do debate. Lua Nova, São Paulo, n.76, p. 49-86, 2009.

AVRITZER, Leonardo. Instituições participativas e desenho institucional: algumas considerações sobre a variação da participação no Brasil democrático. Revista Opinião Pública, Campinas, v. 14, n. 1, p. 43-64, 2008.

CARLOS, Euzeneia. Movimentos sociais e sistema político nas teorias dos movimentos sociais. INTERSEÇÕES [Rio de Janeiro] v.17, n.1, p.15-53, jun. 2015. 
COHEN, Jean; ARATO, Andrew. Social movements and civil society. In: CoHeN, Jean; ArATo, Andrew. Civil Society and Political Theory. Cambridge: MIT Press, 1992.

COHEN, Jean. Strategy or identity: new theoretical paradigms and contemporary social movements. Social Research, v. 52, n.4, p. 663-716, 1985.

DAGNINO, Evelina. Sociedade civil, espaços públicos e construção democrática no Brasil: limites e possibilidades. In: DAGNINO, Evelina (Org.). Sociedade civil e espaços públicos no Brasil. São Paulo: Paz e Terra, 2002, p.279-303.

DARON, Vanderléia, L. P. Um grito lilás: cartografia da violência às mulheres do campo e da floresta. Brasília: Secretaria de Políticas para as Mulheres, 2009.

DELLA PORTA, Donatella; DIANNI, Mario. Social Movements: an introduction. 2a ed. Oxford: Blackwell, 1999.

DowBoR, Monika. Para além de recursos para as mobilizações: organizações de movimentos sociais como ação política. 38 ncontro Anual da ANPOCS. Anais... Caxambu, out. 2014.

FARAH, Marta. F.S. Gênero e políticas públicas. Estudos Feministas. Florianopolis, v. 12, n. 1, p. 47, jan/-abr, 2004.

GoHN, Maria da Glória. Teoria dos movimentos sociais: paradigmas clássicos e contemporâneos. São Paulo: Loyola, 1997.

Gutterres, Anelise; Aguião, Adriana V.S. Percursos, tensões e possibilidades da participação de movimentos de mulheres e feminista nas políticas governamentais. In: LOPEZ, José; HEREDIA, Beatriz (org.). Movimentos sociais e esfera pública: o mundo da participação: burocracias, confrontos, aprendizados inesperados. Rio de Janeiro: CBAE, 2014, p. 211-237.

HerediA, Beatriz; CINTRÃo, Rosângela. Gênero e acesso a políticas públicas no meio rural brasileiro. Revista NERA, ano 9, n. 8, jan/jun, 2006.

MATOS, Marlise. Gênero e sexualidade nas políticas públicas: o temor de retrocesso. Teoria e Debate. Edição 149, jun, 2016. Disponível em: <http://www.teoriaedebate. org.br/index.php?q=materias\%2Fsociedade\%2Fgenero-e-sexualidade-naspoliticas-publicas-o-temor-de-retrocesso> Acesso em: 14 jul. 2017.

MeluCCl, Alberto. A invenção do presente: movimentos sociais nas sociedades complexas. Tradução de Maria do Carmo Alves do Bomfim. Petrópolis: Vozes, 2001. OKIN, Susan Moller. Gênero, o público e o privado. Estudos Feministas, Florianópolis, v. 16, n. 2, p. 305-332, mai/ago. 2008.

PAsınAto, Wânia. Oito anos de Lei Maria da Penha. Entre avanços, obstáculos e desafios. Estudos Feministas, Florianópolis, v. 23, n. 2, p. 533-545, mai/ago. 2015.

PINTO, Céli R. J. O feminismo no Brasil: suas múltiplas faces. Fundação Perseu Abramo Coleção Histórias do Povo Brasileiro. São Paulo, 2003.

SARTI, Cynthia. Feminismo no Brasil: uma trajetória particular. Cad. Pesq. São Paulo, v. 64, p. 38-47, fev. 1988.

SeCRetaria de Políticas para as Mulheres (SPM). Mulheres do Campo e da Floresta: diretrizes e ações nacionais. Brasília: Secretaria Nacional de Enfrentamento à Violência contra as Mulheres, 2011a. 
Política Nacional de Enfrentamento à Violência Contra as Mulheres. Brasília: Secretaria Nacional de Enfrentamento à Violência contra as Mulheres, 2011b.

Rede de Enfrentamento à Violência contra as Mulheres. Brasília: Secretaria Nacional de Enfrentamento à Violência contra as Mulheres, 2011c.

Pacto Nacional pelo Enfrentamento à Violência Contra as Mulheres. Brasília: Secretaria Nacional de Enfrentamento à Violência contra as Mulheres, 2011d.

SILIPRANDI, Emma. Mulheres e agroecologia: transformando o campo, as florestas e as pessoas. Rio de Janeiro: Editora UFRJ, 2015.

SILIPRANDI, Emma; CINTRÃo, Rosângela. Mulheres rurais e políticas públicas no Brasil: abrindo espaços para o seu reconhecimento como cidadãs. In: GRISA, Catia; SCHNEIDER, Sergio (Org.). Políticas públicas de desenvolvimento rural no Brasil Porto Alegre: Editora da UFRGS, 2015.

SILVA, Berenice G. A Marcha das Margaridas: resistências e permanências. Dissertação (Mestrado). Universidade de Brasília, Brasília, 2008.

TELES, Maria Amélia de Almeida. Breve história do feminismo no Brasil. São Paulo: Ed. Brasiliense, 1993.

WARren, M. What does participation means today? Political Theory, v. 30, n. 5, 2002.

Mariana de Lima Campos

Possui mestrado em Administração Pública pela Escola de Governo Professor Paulo Neves de Carvalho da Fundação João Pinheiro (EG/FJP). Contato: marianalcampos@gmail.com

Flávia de Paula Duque Brasil

Possui doutorado em Sociologia pela Universidade Federal de Minas Gerais (UFMG). Atualmente é professora da Escola de Governo Professor Paulo Neves de Carvalho da Fundação João Pinheiro (FJP). Contato: flaviaduquebrasil@ gmail.com 
